\title{
Uneven terrain treadmill walking in younger and older adults
}

Ryan J. Downey ${ }^{1 *}$, Natalie Richer ${ }^{1} \#$, Rohan Gupta ${ }^{1}$, Chang Liu ${ }^{1}$, Erika M. Pliner ${ }^{1}$, Arkaprava Roy², Jungyun Hwang $^{3}$, David J. Clark ${ }^{3,4}$, Chris J. Hass ${ }^{5}$, Todd M. Manini ${ }^{3}$, Rachael D. Seidler ${ }^{5}$, and Daniel P. Ferris ${ }^{1}$

${ }^{1}$ Department of Biomedical Engineering, University of Florida, Gainesville, FL, United States of America

${ }^{2}$ Department of Biostatistics, University of Florida, Gainesville, FL, United States of America

${ }^{3}$ Department of Aging and Geriatric Research, University of Florida, Gainesville, FL, United States of America

${ }^{4}$ Brain Rehabilitation Research Center, Malcom Randall VA Medical Center, Gainesville, FL, United States of America

${ }^{5}$ Department of Applied Physiology and Kinesiology, University of Florida, Gainesville, FL, United States of America

${ }^{\# a}$ Current address: Department of Kinesiology and Applied Health, University of Winnipeg, Winnipeg, Manitoba, Canada

${ }^{*}$ Corresponding author

E-mail: RDowney@bme.ufl.edu (RD) 
bioRxiv preprint doi: https://doi.org/10.1101/2022.03.01.482507; this version posted March 4, 2022. The copyright holder for this preprint (which was not certified by peer review) is the author/funder, who has granted bioRxiv a license to display the preprint in perpetuity. It is made available under aCC-BY-NC-ND 4.0 International license.

\section{Abstract}

We developed a method for altering terrain unevenness on a treadmill to study gait kinematics. We attached rigid polyurethane disks $(12.7 \mathrm{~cm}$ diameter, $1.3-3.8 \mathrm{~cm}$ tall) to the treadmill belt using hook-and-loop fasteners. We tested four terrain conditions: Flat, Low, Medium, and High. The main objective was to test the hypothesis that increasing the unevenness of the terrain would result in greater gait kinematic variability. We tested 17 younger adults (age 20-40 years), 25 higher-functioning older adults (age 65+ years), and 29 lowerfunctioning older adults (age 65+ years, Short Physical Performance Battery score $<10$ ). We customized the treadmill speed to each participant's walking ability, keeping the speed constant across all four terrain conditions. Participants completed two 3-minute walking trials per condition. Using an inertial measurement unit placed over the sacrum and pressure sensors in the shoes, we calculated the stride-to-stride variability in step duration and sacral excursion (coefficient of variation; standard deviation expressed as percentage of the mean). Participants also self-reported their perceived stability for each condition. Terrain was a significant predictor of step duration variability, which roughly doubled from Flat terrain to High terrain for all participant groups: younger adults (Flat 4.0\%, High 8.2\%), higher-functioning older adults (Flat 5.0\%, High 8.9\%), lower-functioning older adults (Flat 7.0\%, High 14.1\%). Similarly, all groups exhibited significant increases in sacral excursion variability for all three uneven terrain conditions compared to Flat. Participants were also significantly more likely to report feeling less stable walking over uneven terrain. These findings support the hypothesis that altering terrain unevenness on a treadmill will increase gait kinematic variability and reduce perceived stability in younger and older adults. 
bioRxiv preprint doi: https://doi.org/10.1101/2022.03.01.482507; this version posted March 4, 2022. The copyright holder for this preprint

(which was not certified by peer review) is the author/funder, who has granted bioRxiv a license to display the preprint in perpetuity. It is made available under aCC-BY-NC-ND 4.0 International license.

\section{Introduction}

Mobility impairments limit people's ability to perform activities of daily living and negatively impact quality of life. Improved diagnosis and treatment of mobility impairments requires understanding limitations in walking ability, both from biomechanical and neurological perspectives. A common approach to studying mechanisms responsible for limitations in walking ability is to examine human participants walking under conditions that challenge their control and stability. Limitations in walking ability sometimes only become apparent when individuals experience cognitive or physical challenges while walking.

The dual-task experimental paradigm is a common way to identify limitations in walking ability and control where participants are asked to perform a cognitive task while walking. The concomitant cognitive task may include talking [1-3], memory recall [4,5], arithmetic calculation [3,4,6,7], and visual distraction [3]. Performing the cognitive task requires additional cortical resources, affecting participants' walking behavior and potentially reducing the cortical resources devoted to the act of walking.

Increasing the difficulty level of the walking task is another way to identify limitations in walking ability and control. Participants can experience brief physical perturbations via moveable floor platforms [8-10], rapid acceleration or deceleration of a treadmill belt [11-14], or by pushes and pulls from a machine or experimenter $[11,15,16]$. These studies provide information about human locomotor control, including how people recover from discrete disturbances to maintain balance and how they adapt their gait patterns to reduce the risk of falls.

Another way to increase walking difficulty is to alter the terrain. Uneven terrain is common in natural environments and is an important dimension of mobility that is often neglected in research and the clinical care of individuals with mobility impairments [17]. Walking over uneven terrain requires continuous cognitive and physical effort. This contrasts with dual-task paradigms, which distract participants cognitively, and with discrete physical perturbations, which challenge participants intermittently.

Some studies have used modified treadmills to create uneven surfaces [18-22]. However, previous studies examined only one uneven surface and compared it with normal treadmill walking. Previous studies did not parametrically alter the unevenness of the terrain across multiple levels. Similarly, previous uneven terrain treadmill studies focused on healthy young adults. Previous studies have not examined uneven terrain treadmill walking in older adults. 
bioRxiv preprint doi: https://doi.org/10.1101/2022.03.01.482507; this version posted March 4, 2022. The copyright holder for this preprint

The overall goal of this paper was to determine how younger and older adults adjusted their walking kinematics to parametric variations in uneven terrain on a treadmill. We designed and tested a novel uneven terrain treadmill surface constructed with lightweight and easy-to-change materials. Three groups of participants (younger adults, higher-functioning older adults, and lower-functioning older adults) walked on four terrain conditions (Flat, Low, Medium, High). Our primary outcome measures were step duration variability and variability in the excursion of the sacrum. We hypothesized that there would be greater variability in the step duration and sacral excursion for the uneven terrain conditions compared to the flat terrain. We expected that the variability measures would increase with terrain unevenness. We also hypothesized that participants would report feeling less stable over uneven terrain compared to flat terrain.

\section{Materials and methods}

This experiment was part of a larger study (Mind in Motion) that is still ongoing [23]. As part of that study, participants in this experiment were equipped with a wireless electroencephalography (EEG) system for the entirety of the data collection. The EEG setup was not cumbersome for participants and did not likely impact their walking kinematics. Certain other details in the present methodology also relate back to the design of the larger study.

\section{Participant characteristics}

The participants for this study were 17 healthy younger adults aged 20 to 40 years (10 females, 7 males; mean age $\pm S D=23 \pm 4$ years) as well as 54 older adults at least 65 years of age (76 \pm 6 years; 30 females, 24 males). Of the 54 older adults, 25 were higher-functioning (74 74 years; 11 females, 14 males) and 29 were lower-functioning (77 \pm 7 years; 19 females, 10 males). Mobility function was determined using the Short Physical Performance Battery score [24]; those with scores < 10 were considered lower-functioning while those with scores $\geq 10$ were considered higher-functioning. All participants were able to complete a $400 \mathrm{~m}$ walk test in less than 15 minutes without help from another person or a walker. Full inclusion and exclusion criteria are outlined in [23]. All participants provided informed consent before participating in the experiment, and the protocol was approved by the Institutional Review Board for the protection of human subjects at the University of Florida. 
bioRxiv preprint doi: https://doi.org/10.1101/2022.03.01.482507; this version posted March 4, 2022. The copyright holder for this preprint (which was not certified by peer review) is the author/funder, who has granted bioRxiv a license to display the preprint in perpetuity. It is made available under aCC-BY-NC-ND 4.0 International license.

\section{Uneven treadmill design and customization}

We modified a slat belt treadmill (PPS 70 Bari-Mill, Woodway, Waukesha, WI, USA; $70 \mathrm{~cm} \times 173 \mathrm{~cm}$ walking surface) by adding rigid foam disks to the walking surface to create uneven terrain (Fig $1 \mathrm{~A})$. The lightweight yet rigid disks were made from polyurethane with a density of 8 pounds per cubic foot $\left(128 \mathrm{~kg} / \mathrm{m}^{3}\right)$ using a circular free-rise mold (Blockwire Manufacturing LLC, Goshen, AL, USA). We attached the disks to the treadmill using self-adhesive hook-and-loop fasteners so we could easily switch between multiple sets of uneven terrain. The loop side was attached to the treadmill surface and the hook side was attached to the disks. The spatial configuration of the disks was the same for each version of uneven terrain tested. The layout was carefully planned in order to avoid large gaps and adjacent disks, so the unevenness of the terrain could not be avoided. To accommodate the height of the disks, we removed the treadmill's incline mechanism and placed the treadmill on wooden blocks to increase the clearance with the floor. A supplementary diagram is provided in S1 Fig. so that others may replicate the spatial configuration we used.

[Insert Fig 1 about here]

We tested four terrain conditions which we named Flat, Low, Medium, and High (Fig 1B). For the Low, Medium, and High conditions, rigid foam disks were added to the walking surface. Each disk was $12.7 \mathrm{~cm}$ diameter, but the height varied by condition. The Low condition consisted entirely of $1.3 \mathrm{~cm}$-high disks which were painted yellow. The Medium surface had two disk heights: $50 \%$ were $1.3 \mathrm{~cm}$ tall and $50 \%$ were $2.5 \mathrm{~cm}$ tall, all painted orange. The High surface had three unique disk heights: $20 \%$ were $1.3 \mathrm{~cm}$ tall, $30 \%$ were $2.5 \mathrm{~cm}$ tall, and $50 \%$ were $3.8 \mathrm{~cm}$ tall, all painted red. For the Flat condition, no disks were added to the walking surface, but green circles were painted on the treadmill belt surrounding each piece of hook-and-loop fastener which was also green. This was to ensure that the visual nature of the Flat condition was similar to the other terrain conditions. For the Medium and High conditions, which use a mixture of disk heights, the placement was consistent across participants. We achieved this by labeling the location of each type of disk by placing small pieces of color-coded duct tape next to the hook-and-loop fasteners on the walking surface and under each disk. 
bioRxiv preprint doi: https://doi.org/10.1101/2022.03.01.482507; this version posted March 4, 2022. The copyright holder for this preprint (which was not certified by peer review) is the author/funder, who has granted bioRxiv a license to display the preprint in perpetuity. It is made available under aCC-BY-NC-ND 4.0 International license.

\section{Experiment protocol}

\section{Treadmill speed calculation}

We customized the treadmill speed to each participant based on their self-selected overground walking speed. Participants walked across an overground version of the Flat, Low, Medium, and High terrain, and we used a stopwatch to record the time it took to travel the middle 3-meter portion. We calculated the overground walking speed for each terrain as the average of three trials. We then took the participant's slowest average overground speed (slowest terrain) and multiplied it by $75 \%$ to calculate a treadmill speed to target. Because the speed was later kept constant across all treadmill conditions, we wanted to ensure the speed was not too fast such that participants could not complete the more difficult conditions. Participants had an opportunity to familiarize themselves with uneven treadmill walking while the treadmill speed slowly increased toward the targeted speed. We observed the participants and asked for their feedback as the speed progressively increased. We increased the speed until the participant verbally confirmed we had reached the fastest walking speed they were comfortable with or until we reached the original target speed. In either case, the participantspecific treadmill speed was kept constant across all four terrain conditions in subsequent testing. The overground self-selected walking speeds are depicted in Fig 2 for each participant group and terrain, along with the speed that was used in the treadmill trials.

\section{[Insert Fig 2 about here]}

\section{Pseudorandomized conditions}

Participants performed a block of two treadmill walking trials per condition. Each trial was 3-minutes long with breaks in between as needed. Conditions were pseudorandomized. Specifically, the order was selected randomly with the stipulation that the less uneven (Flat, Low) and more uneven (Medium, High) conditions be counterbalanced. For example, if the first block was Flat or Low, then the second block was Medium or High, and vice versa. This led to 8 unique orders of conditions. 
bioRxiv preprint doi: https://doi.org/10.1101/2022.03.01.482507; this version posted March 4, 2022. The copyright holder for this preprint

(which was not certified by peer review) is the author/funder, who has granted bioRxiv a license to display the preprint in perpetuity. It is made available under aCC-BY-NC-ND 4.0 International license.

\section{Participant safety}

Participants wore a safety harness attached to an overhead rail (Portable Track System, Solo-Step, North Sioux City, SD, USA) to catch them in the event of a fall. Research staff members were present directly behind the treadmill and to the sides, generally out of view, to ensure that participants did not stray off the treadmill accidentally. The treadmill's handrails were removed so that participants could not hold onto them for support during walking. Participants were allowed to briefly grab onto an experimenter's arm in the immediate moment of a stumble or loss of balance, if it were to occur. However, in this scenario, they were also instructed to let go of support as quickly as possible and return to normal walking. Similarly, we allowed participants to hold onto experimenters' arms for support while the treadmill was accelerating or decelerating, but we required participants to let go and walk on their own before a trial could officially start. If a participant felt they could not walk without support for a given condition, the condition was skipped, and data were not recorded. This only occurred for one participant, an older lower-functioning adult who did not want to perform the High condition without letting go of support.

\section{Data processing}

\section{Temporal measures}

We recorded the ground reaction force of each foot with capacitive shoe insole sensors (loadsol 1-sensor, Novel Electronics Inc., St. Paul, MN, USA) at $200 \mathrm{~Hz}$. These sensors have been previously validated against an instrumented treadmill [25]. We used custom MATLAB scripts for all data processing. We computed heel strike events for each foot as the time points when the ground reaction forces reached $20 \mathrm{~N}$. For each gait cycle, we calculated the step duration as the time difference between heel strikes of opposing feet. We then calculated the mean and standard deviation of the step duration across all gait cycles and removed outliers more than 2.5 standard deviations away from the mean. Step durations that were classified as outliers were not reflective of steady state walking (e.g., shorter or longer step durations due to a brief stumble or loss of balance). We then recalculated the mean step duration and its standard deviation. Finally, we calculated the variability of the step duration as the coefficient of variation (standard deviation expressed as a percentage of the mean). The step duration and step duration variability measures were averaged across both legs within a trial and then averaged across the two trials within each terrain condition. 
bioRxiv preprint doi: https://doi.org/10.1101/2022.03.01.482507; this version posted March 4, 2022. The copyright holder for this preprint (which was not certified by peer review) is the author/funder, who has granted bioRxiv a license to display the preprint in perpetuity. It is made available under aCC-BY-NC-ND 4.0 International license.

\section{Spatial measures}

We placed an inertial measurement unit (IMU) over the sacrum using an elastic belt and sampled the data at $128 \mathrm{~Hz}$ (Opal, APDM Inc., Portland, OR, USA). IMU data were offline synchronized to the insole ground reaction force sensors so the IMU data could later be analyzed with respect to each stride (gait cycle). For each walking trial, we recreated the trajectory of the sacrum using the IMU data. For each stride, we calculated the peak-to-peak excursion of the sacrum in the anteroposterior and mediolateral directions. For each direction we then calculated the variability in sacral excursion from stride to stride as the coefficient of variation. Similar to the temporal measures, we averaged the spatial variability measures across two trials within each terrain condition. Further details regarding the sacrum displacement estimation are provided in Fig 3.

[Insert Fig 3 about here]

\section{Perceived stability}

To obtain a subjective rating of participants' perceived stability, we used a modified version of the Rate of Perceived Stability scale from [26]. The modified scale spans five unique ratings from steady to very unbalanced. After each 3-minute walking trial, we asked participants to rate the trial by asking them a series of questions. We first asked, "did it feel like work to keep your balance?" Based on their answer (Yes or No), we either assigned a stability rating or proceeded to ask the next question. The flow chart for assigning a perceived stability score is provided in Fig 4. Stability ratings were not averaged across trials within a condition since we wanted to maintain the original set of 5 unique ratings (no half ratings) for subsequent analysis (ordinal logistic regression).

[Insert Fig 4 about here]

\section{Statistical methods}

We applied a linear mixed effects model to each of our four behavioral outcome measures (step duration, step duration variability, anteroposterior excursion variability, and mediolateral excursion variability) using $R$ 
bioRxiv preprint doi: https://doi.org/10.1101/2022.03.01.482507; this version posted March 4, 2022. The copyright holder for this preprint

(which was not certified by peer review) is the author/funder, who has granted bioRxiv a license to display the preprint in perpetuity. It is made available under aCC-BY-NC-ND 4.0 International license.

(carData and nlme packages). The first predictor for each model was the terrain (Flat, Low, Medium, High) and the second was the participant group (younger adults, higher-functioning older adults, lower-functioning older adults). We also included terms for group-terrain interactions. The baseline values for the terrain and group variables were selected as Flat and higher-functioning older adults, respectively. We accounted for participant specific inhomogeneity through random effects after adjusting for terrain effect, group effect and their interactions. We used a p-value cutoff of 0.05 for determining statistically significant effects.

We used the coefficient of variation to quantify walking variability, so the raw values are reported as percentage points. Possible values range from 0\% (perfectly steady walking) to 100\% (max theoretical unsteadiness, standard deviation $=100 \%$ of the mean). In the Results, we report the group and terrain effects in terms of the original units (percentage points); we do not take one coefficient of variation and divide it by another. For example, if the coefficient of variation increased from $4 \%$ (condition A) to $6 \%$ (condition B), we later report this effect as an increase of +2 points rather than an increase of $+50 \%$.

Data from three lower-functioning individuals were excluded from the analysis because they did not perform the protocol as intended. These participants walked at the slowest treadmill speeds of all $(0.05,0.05$, $0.07 \mathrm{~m} / \mathrm{s}$ ). We excluded the data from these three participants because of technical issues arising from the slow treadmill walking speeds which caused these participants to frequently run out of room at the front of the treadmill and pause their walking. These pauses, which were not necessarily reflective of being challenged, were difficult to differentiate from pauses in walking due to being challenged by the terrain condition. Therefore, we limited our dataset to the 17 younger adults and 54 older adults who could walk on the uneven terrain treadmill at speeds $\geq 0.1 \mathrm{~m} / \mathrm{s}$.

There were missing values for 2 out of 284 behavioral observations (71 participants, 4 conditions per participant). In one case, the participant was a lower-functioning older adult who was unable to perform the High condition but could complete the other uneven terrain walking conditions. In the second case, we encountered a technical issue that prevented us from recording the Low condition for a lower-functioning older adult (depleted batteries). Since the proportion of missing observations was small, the models were fit without the missing data (using 282 out of 284 observations). 
bioRxiv preprint doi: https://doi.org/10.1101/2022.03.01.482507; this version posted March 4, 2022. The copyright holder for this preprint (which was not certified by peer review) is the author/funder, who has granted bioRxiv a license to display the preprint in perpetuity. It is made available under aCC-BY-NC-ND 4.0 International license.

For the perceived stability outcome measure, we fit an ordinal logistic regression model rather than a linear model since the values are drawn from a discrete set of ordered ratings (steady, unsteady, mildly unbalanced, etc.). Along these lines, we purposefully did not average the two trials together within a condition as that would introduce half-ratings (e.g., halfway between steady and unsteady). Instead, we kept the ratings from the individual trials separate (repeated measures). Thus, there were approximately twice as many observations for this analysis. Terrain and Participant Group were used as predictors with the baseline values set to Flat and higher-functioning older adults, respectively. Confidence intervals $(95 \%)$ were constructed on the odds ratio for each model term to check for statistically significant effects. Interaction terms were not included for the perceived stability outcome measure due to issues with model convergence.

\section{Results}

\section{Step duration}

Terrain was a significant predictor of step duration, which decreased as terrain unevenness increased (Fig 5). Compared to flat treadmill walking, which had a baseline step duration of 0.74 seconds in higherfunctioning older adults, step durations were $0.08,0.10$, and 0.14 seconds shorter for the Low, Medium, and High terrain, respectively. Step durations were significantly shorter for High terrain ( $p$-value $=0.0009$ ) and Medium terrain $(p$-value $=0.017)$ compared to Flat. The step duration for Low terrain was not significantly different from Flat $(p-$ value $=0.06)$. Compared to the higher-functioning older adults, the lower-functioning group tended to walk with longer step durations $(+0.08$ seconds; $p$-value $=0.06)$ over Flat terrain, and the younger adults tended to walk with shorter step durations over Flat terrain $(-0.04$ seconds; $p$-value $=0.39)$, but neither effect was significant. There were no significant interactions between Terrain and Participant Group. Thus, all groups showed a significant effect of decreased step duration for the High and Medium terrain compared to Flat. A table with the full statistical results is provided in S2 Table.

[Insert Fig 5 about here] 
bioRxiv preprint doi: https://doi.org/10.1101/2022.03.01.482507; this version posted March 4, 2022. The copyright holder for this preprint (which was not certified by peer review) is the author/funder, who has granted bioRxiv a license to display the preprint in perpetuity. It is made available under aCC-BY-NC-ND 4.0 International license.

\section{Step duration variability}

Terrain was a significant predictor of step duration variability, which increased as terrain unevenness increased (Fig 6) and roughly doubled in value from Flat to High for all participant groups. Compared to flat treadmill walking which had a baseline step duration variability of $5.0 \%$ in higher-functioning older adults, variability increased by $1.7,2.2$, and 3.9 points for the Low, Medium, and High terrain, respectively. This increase was significant for all uneven terrain ( $p$-values: Low $=0.02$, Medium $=0.002$, High $<0.0001$ ). Compared to higher-functioning older adults, the lower-functioning group walked with significantly greater step duration variability over Flat terrain $(+2.0$ points; $p$-value $=0.004)$. Meanwhile, younger adults walked with less step duration variability over Flat terrain compared to higher-functioning older adults, but it was not significant $(-1.0$ points; $p$-value $=0.18$. There was only one significant interaction term in the model which was the term corresponding to High terrain and lower-functioning older adults $(+3.2$ points; $p$-value $=0.0009)$. This term indicated that the main effect of the High terrain (relative to Flat) was stronger for lower-functioning older adults than for higher-functioning older adults. Thus, all groups showed a significant effect of increased step duration variability for the Low, Medium, and High terrain conditions compared to Flat. A table with the full statistical results is provided in S3 Table.

[Insert Fig 6 about here]

\section{Anteroposterior sacral excursion variability}

Terrain was a significant predictor of anteroposterior sacral excursion variability, which increased as terrain unevenness increased (Fig 7). Compared to flat treadmill walking which had a baseline variability of $21.4 \%$ in higher-functioning older adults, variability increased by $3.7,5.3$, and 9.0 points for the Low, Medium, and High terrain, respectively. This increase was significant for all uneven terrain ( $p$-values: Low $=0.014$, Medium $=0.0004$, High < 0.0001). Compared to the higher-functioning older adults, the lower-functioning group walked with significantly increased anteroposterior variability over flat terrain $(+5.6$ points; $p$-value $=0.0001)$. Meanwhile, the younger adults walked with significantly less variability over flat terrain $(-5.6$ points; $p$-value $=0.0009)$. There 
bioRxiv preprint doi: https://doi org/10.1101/2022 03 01.482507: this version posted March 4, 2022. The copyright holder for this preprint (which was not certified by peer review) is the author/funder, who has granted bioRxiv a license to display the preprint in perpetuity. It is made available under aCC-BY-NC-ND 4.0 International license.

were no significant interaction effects. Thus, all groups showed a significant effect of increased sacral variability in the anteroposterior direction for the Low, Medium, and High terrain conditions compared to Flat. A table with the full statistical results is provided in S4 Table.

[Insert Fig 7 about here]

\section{Mediolateral sacral excursion variability}

Terrain was also a significant predictor of mediolateral excursion variability, which increased as terrain unevenness increased (Fig 8). Compared to flat treadmill walking which had a baseline variability of $12.5 \%$ in higher-functioning older adults, variability increased by 2.8, 4.1, and 7.1 points for the Low, Medium, and High terrain, respectively. This increase was significant for all uneven terrain ( $p$-values: Low $=0.045$, Medium $=0.004$, High < 0.0001). Compared to the higher-functioning older adults, the younger adults walked with significantly increased mediolateral variability over flat terrain $(+3.8$ points; $p$-value $=0.014)$. The lower-functioning group walked with decreased baseline variability compared to the higher-functioning group, but it was not significant (1.6; $p$-value $=0.22$ ). There were no significant interaction effects. All groups showed a significant effect of increased sacral variability in the mediolateral direction for the Low, Medium, and High terrain conditions compared to Flat. A table with the full statistical results is provided in S5 Table.

[Insert Fig 8 about here]

\section{Perceived stability}

There was a significant effect of Terrain on the perceived stability rating. Compared to Flat, all uneven terrain conditions were significantly more likely to be perceived as less stable, and the odds of a less stable rating increased with terrain unevenness (odds ratios: Low=4.2, Medium=17.0, High=68.0). Lower-functioning adults were 2.8 times more likely to report feeling less stable over flat terrain than higher-functioning older adults 
bioRxiv preprint doi: https://doi org/10.1101/2022.03.01.482507; this version posted March 4, 2022. The copyright holder for this preprint

(odds ratio $=2.8$ ). There was no significant difference between younger adults' and higher-functioning older adults' perceived stability over flat terrain. The $95 \%$ confidence interval for the corresponding odds ratio contained $1([0.72,2.05])$. Interaction terms unfortunately could not be included in this model due to issues with model convergence. Fig 9 displays the frequency at which each terrain condition was rated a particular stability score by each participant group. A table with the full statistical results is provided in S6 Table.

[Insert Fig 9 about here]

\section{Discussion}

As hypothesized, there were significant increases in step duration variability (Fig 6) and sacral excursion variability, both in anteroposterior (Fig 7) and mediolateral (Fig 8) directions, for all three uneven terrain conditions compared to Flat. In addition to the kinematic measures, we found that participants' perceived stability was affected by the type of terrain (Fig 9). Compared to flat walking, participants were significantly more likely to report feeling less stable over uneven terrain. Altogether, these results indicate that adjusting the unevenness of the terrain on a treadmill surface challenged participants' gait.

The effect of uneven terrain was similar between the three participant groups (younger adults, higherfunctioning older adults, and lower-functioning older adults). All groups demonstrated significantly increased kinematic variability over uneven terrain. This effect was consistent for all three of our variability measures and for all three uneven terrain conditions, compared to Flat. Additionally, only 1 of the 24 Group-Terrain interaction terms we tested was significant. In that one case, the interaction term only served to amplify the main effect of High condition for older lower-functioning adults, rather than cancel it out. Thus, the uneven terrain treadmill surface provided a suitable challenge to stability in multiple populations of individuals.

A limited comparison can be made between our data and those from Santuz et al. [19]. In [19], the authors focused on how uneven terrain affected muscle synergies and Lyapunov exponents, abstract metrics of stability compared to the kinematic variability metrics we used (see [27] for a summary of available stability measures). 
bioRxiv preprint doi: https://doi.org/10.1101/2022.03.01.482507; this version posted March 4, 2022. The copyright holder for this preprint

Santuz et al. [19] found no difference in cadence between smooth and uneven terrain in younger adults. Because the treadmill speed was fixed, the average step duration and cadence were inversely related to each other. Thus, their finding that cadence did not change with uneven terrain is similar to our finding that step duration was significantly different for the Medium and High terrain but not for Low.

A closer match to our study is the experiment by Voloshina et al. [21]. In [21], the average step duration decreased from 0.57 seconds to 0.54 seconds when comparing flat to uneven terrain in younger adults. In the present study, the average step duration decreased from 0.70 seconds to 0.67 seconds when comparing the Flat to the High condition in younger adults. Thus, the effect of uneven terrain on step duration in younger adults was small, but similar between the studies (-0.03 seconds). Step durations were longer in the present study than reported in [21], for both flat terrain and uneven terrain. This was most likely due to differences in walking speed between the studies. In [21], the treadmill speed was fixed at $1 \mathrm{~m} / \mathrm{s}$ for all participants. In the present study, the speed was tailored to each participant, based on their self-selected overground speed (Fig 2; average treadmill speed $=0.78 \mathrm{~m} / \mathrm{s}$ for younger adults). In [21], step duration variability was originally reported as a standard deviation. Therefore, we divided this value by the mean step duration to calculate an equivalent value that would be more directly comparable to our results (coefficient of variation). In [21], step duration variability increased from approximately $2.3 \%$ to $3.3 \%$ (+1 point) whereas it increased from $4.0 \%$ to $8.2 \%$ ( +4.2 points) for younger adults in the present study. This indicates that the effect of the High terrain in the present study was stronger than in [21]. This is likely due to the fact that the maximum unevenness was greater for the present study (3.8 $\mathrm{cm}$ versus $2.5 \mathrm{~cm}$ ), as well as the fact that the terrain layout was less regular and therefore less predictable than in [21].

In Kent et al. [20], the authors measured the movement of the center of mass with a motion capture system as younger adults walked on flat and uneven terrain. This metric was similar to the sacral excursion metric in the present paper. Because Kent et al. [20] separately reported the mean and standard deviation of the excursion from stride to stride, rather than combining the values into a single coefficient of variation, and because exact values of the summary statistics were not provided in text, we estimated equivalent values from data in Figs $3 \mathrm{~A}$ and $4 \mathrm{~A}$ in [20]. Nevertheless, average values of sacral excursion variability in the two studies were comparable to each other. In the anteroposterior direction, excursion variability increased from approximately 
bioRxiv preprint doi: https://doi.org/10.1101/2022.03.01.482507; this version posted March 4, 2022. The copyright holder for this preprint

(which was not certified by peer review) is the author/funder, who has granted bioRxiv a license to display the preprint in perpetuity. It is made available under aCC-BY-NC-ND 4.0 International license.

$22 \%$ to $28 \%$ (+6 points) in [20], compared with an increase from $16 \%$ to $23 \%(+7$ points) for younger adults in the present study. In the mediolateral direction, excursion variability increased from approximately $15 \%$ to $19 \%$ (+4 points) in [20], compared with an increase from $16 \%$ to $21 \%(+5$ points) for younger adults in the present study. Differences in baseline variability could be due to differences in how the excursion was measured (motion capture system versus inertial measurement unit); or due to the fact that we had to approximate equivalent values to compare. It could also be related to differences in treadmill size. The dimensions of the walking surface in [20] were $153 \mathrm{~cm}$ long by $56 \mathrm{~cm}$ wide (TRM 731, Precor, Woodinville, WA, USA), compared with $173 \mathrm{~cm}$ long by $70 \mathrm{~cm}$ wide in the present study (PPS 70 Bari-Mill, Woodway, Waukesha, WI, USA). Thus, participants had $11 \%$ more space to move anteroposteriorly and $25 \%$ more space to move mediolaterally in the present study. Additionally, the treadmill in [20] had rails to the left and right of the participants which could further limit the range of mediolateral movement, whereas we purposefully removed them.

In addition to our behavioral results, which agreed with previous results in the literature, our study also tested a subjective measure of stability. Specifically, we employed a modified version of the Rate of Perceived Stability, which was previously used to assess the level of balance exercise intensity posed to participants [26]. Few studies have recorded subjective measures of stability during balance challenging walking tasks. Our results indicated that participants were far more likely to feel less stable over uneven terrain than flat terrain (Low $=4$ times; Medium = 17 times; and High = 68 times more likely).

This was the first uneven terrain treadmill study to include multiple participant populations. Previous uneven treadmill studies [18-22] included between 1-19 younger adults whereas we included 17 younger adults, 25 older higher-functioning adults, and 29 older lower-functioning adults. We detected significant differences between the participant groups on the Flat terrain, but that was not the focus of our study. Our primary motivation was to determine if the uneven terrain treadmill apparatus could challenge walking, regardless of baseline walking performance. We verified that the effect of the terrain was similar across all groups, while accounting for participant-specific and group-specific differences in baseline walking performance. Differences in walking variability between the groups at baseline could be due to other confounding variables such as the participantspecific treadmill speed which we did not control for in the statistical models of the present study. Again, this was because our primary objective was to examine the within-subjects effect of terrain. Because the speed was 
bioRxiv preprint doi: https://doi.org/10.1101/2022.03.01.482507; this version posted March 4, 2022. The copyright holder for this preprint (which was not certified by peer review) is the author/funder, who has granted bioRxiv a license to display the preprint in perpetuity. It is made available under aCC-BY-NC-ND 4.0 International license.

constant across terrain conditions within a given participant and because participant-specific terms were already included in the model, adding the treadmill speed as a covariate would not change the within-subjects effect of terrain. As the parent study to this work is still actively enrolling participants [23], future analysis could examine differences between participant groups in greater detail with a larger dataset with greater statistical power.

In previous uneven terrain treadmill literature, only one uneven terrain condition was tested and compared to flat walking [19-22]. Further, previous designs were not conducive to testing multiple difficulty levels, with terrain that can be removed quickly and easily. In [19], commercially available uneven terrain floor panels (Terrasensa Classic, Hübner, Kassel, Germany) were modified and attached to a treadmill. It was unclear how the terrain was attached, and the setup could be cumbersome if adapted to have multiple difficulty levels, based on the weight of the individual floor panels. The uneven treadmill in [20] is composed of many handshaped wooden slats with a maximum height difference of $2.2 \mathrm{~cm}$. Due to the large number of pieces, replacing the surface would likely be time consuming if more conditions were developed. In [21], a secondary belt was constructed from a non-stretch canvas and secured to the treadmill, equipped with wooden blocks. The large size and weight of the setup could make it difficult to transport and store. Lastly, the treadmill in [22] had a wooden surface with a maximum height difference of $1.27 \mathrm{~cm}$. No further details were given on the terrain's construction. In previous designs there was no easy way to vary the difficulty of the uneven terrain on demand. Meanwhile, the present design offers a lightweight option with the ability to quickly switch between different terrain conditions.

In future work, this treadmill setup will be used to probe brain activity during walking [23], where multiple levels of task difficulty are needed to analyze the data within the well-supported Compensation Related Utilization of Neural Circuits Hypothesis framework [28]. Along these lines, the ability to parametrically control walking difficulty could help disambiguate dysfunctional neural processes from compensatory neural processes in future research [29]. In the present study, however, our primary objective was not to directly evaluate the gradation in difficulty between each uneven terrain, but rather to verify that each of the uneven terrain conditions challenged participants' walking compared to Flat. For this reason, we did not perform post hoc analyses to examine the pairwise differences between each uneven terrain condition. However, the present results still demonstrate a clear trend of increased kinematic variability as unevenness increases, both visually (Figs 6,7 , and 8 ) and as 
bioRxiv preprint doi: https://doi.org/10.1101/2022.03.01.482507; this version posted March 4, 2022. The copyright holder for this preprint

(which was not certified by peer review) is the author/funder, who has granted bioRxiv a license to display the preprint in perpetuity. It is made available under aCC-BY-NC-ND 4.0 International license.

evidenced by the model coefficients consistently increasing in magnitude from Low to Medium to High (S3 Table, S4 Table, S5 Table). Thus, in future work, we expect to see a measurable effect of the terrain condition on brain activity. Future work could also focus on obtaining a more thorough understanding of the biomechanics of uneven terrain walking, for example, by examining other outcome measures in addition to the four presented in this study.

Along these lines, we expect that other researchers will benefit from using our treadmill setup to answer various biomechanical or neuromechanical questions. For example, this apparatus could be a useful tool to track mobility impairments and recovery. It could also potentially be used as a training paradigm to enhance recovery in the future. Our results have also demonstrated that the gradation in difficulty was similar between younger adults, higher-functioning older adults, and lower-functioning older adults, suggesting that it could be applied to a variety of populations including those with mobility impairment. Because the walking task difficulty is easily modified, either by changing the height or spacing of the disks or the speed of the treadmill, the apparatus is easily adaptable to other researchers' or clinicians' needs.

To encourage others to recreate and test our uneven terrain treadmill apparatus for their own research in the future, we chose to keep the design relatively simple without permanently modifying the treadmill surface. Attaching lightweight but rigid foam disks to the treadmill with self-adhesive hook-and-loop fasteners was a convenient and easy method to modify terrain difficulty on demand. We are providing a schematic of the spatial layout of the disks relative to the treadmill belt in S1 Fig, so that others can replicate the three uneven terrain conditions we tested. Likewise, we are providing the underlying data for the statistical analyses in S7 Spreadsheet, so that others can replicate our findings or repurpose the data to answer their own research questions.

Note that certain design choices were made which should be considered by those attempting to replicate our apparatus, as they may limit the ability to answer certain research questions. First, to allow the polyurethane disks to fit under the treadmill, we had to remove the incline mechanism and raise the treadmill on wooden blocks. Our treadmill would therefore not allow us to test the effect of these uneven terrain conditions on an inclined surface. This might be possible with other treadmills with different incline mechanisms. Second, because we designed the treadmill so the polyurethane disks could easily be removed, they would occasionally fall off if 
bioRxiv preprint doi: https://doi.org/10.1101/2022.03.01.482507; this version posted March 4, 2022. The copyright holder for this preprint

improperly attached or in the event of a foot accidentally kicking the disks from the side (mid swing) rather than the foot landing onto the disks from above. This could be viewed as an advantage, because a rigidly fixed disk is more likely to cause a trip. However, other researchers might prefer the disks to stay firmly attached during testing. In this case, more permanent solutions might be necessary. In the present study, if a piece of the terrain were to come loose during the trial, we instructed participants to ignore it and keep walking as if nothing happened. Another consideration for those interested in replicating the treadmill is that we chose to place force sensors in participants' shoes to extract gait events since the treadmill we used did not have its own force sensors. Thus, it is unclear how the uneven terrain would impact the raw measurements coming from a commercially available force-instrumented treadmill. Note that in [18], the authors were able to create a custom force-instrumented uneven terrain treadmill by placing the treadmill over two force plates. As a final consideration, note that we applied the terrain to a slat belt treadmill. This design has not been validated on a treadmill with a continuous belt.

Regarding the testing methodology, one potential limitation of this study is that we used an inertial measurement unit to recreate the trajectory of the sacrum rather than motion capture, which would have been more accurate. Additionally, due to the length constraint of a treadmill, participants have a limited amount of time to plan compared to overground walking. This could be considered a benefit or a limitation, depending on the specific research question.

\section{Conclusions}

We created a novel uneven terrain treadmill design out of lightweight and easy-to-change materials (polyurethane disks and hook-and-loop fasteners). We tested four variations of terrain (Flat, Low, Medium, High), and the results showed consistent increases in kinematic variability as the terrain unevenness increased. The effect of uneven terrain was consistent across all three participant groups. These findings indicate that the uneven terrain treadmill surface was a suitable apparatus for challenging walking in multiple populations. In the future, this treadmill could be used as a tool to study other populations walking over uneven terrain. For example, it could be used to track mobility impairments and recovery after stroke; or as a therapeutic intervention; or as a 
bioRxiv preprint doi: https://doi.org/10.1101/2022 03.01.482507; this version posted March 4, 2022. The copyright holder for this preprint (which was not certified by peer review) is the author/funder, who has granted bioRxiv a license to display the preprint in perpetuity. It is made available under aCC-BY-NC-ND 4.0 International license.

testbed to evaluate the efficacy of assistive devices, such as prosthetics for amputees and exoskeletons for individuals with spinal cord injury. 


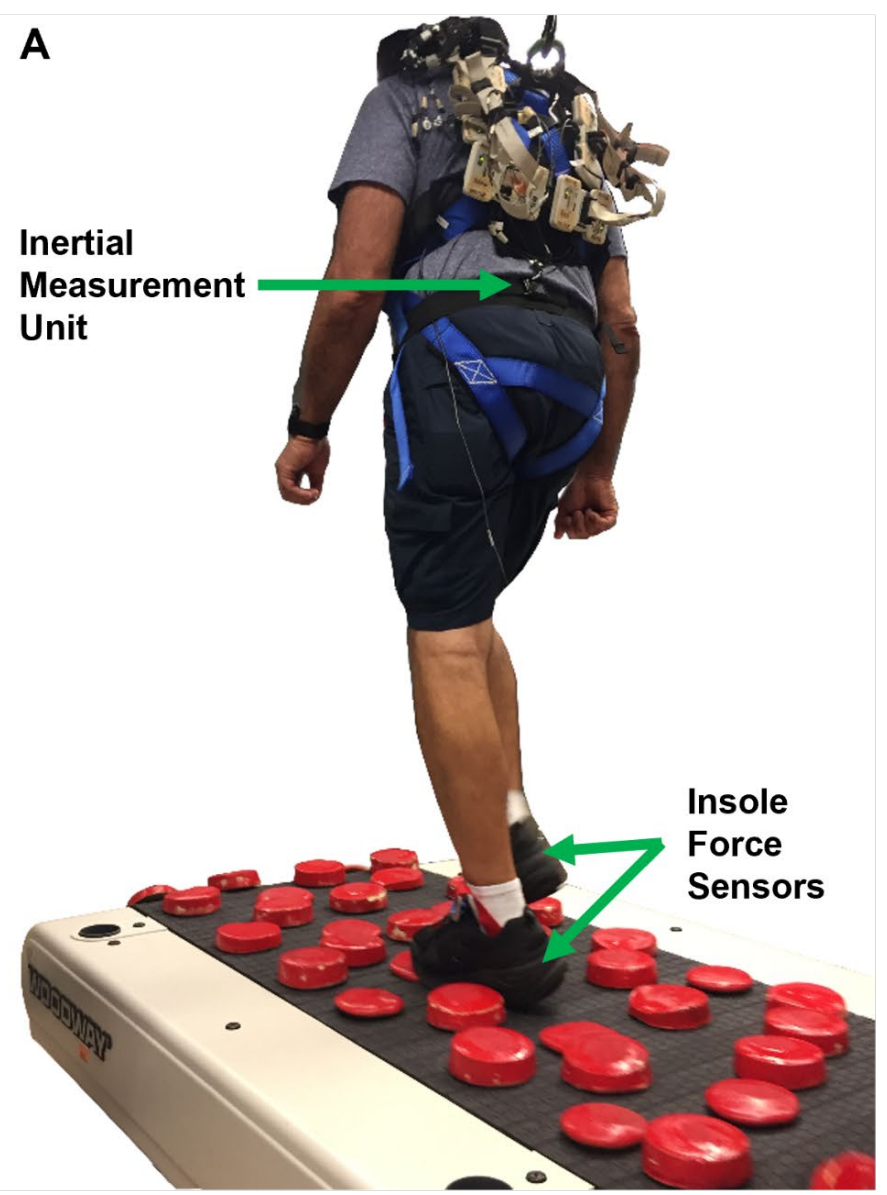

B
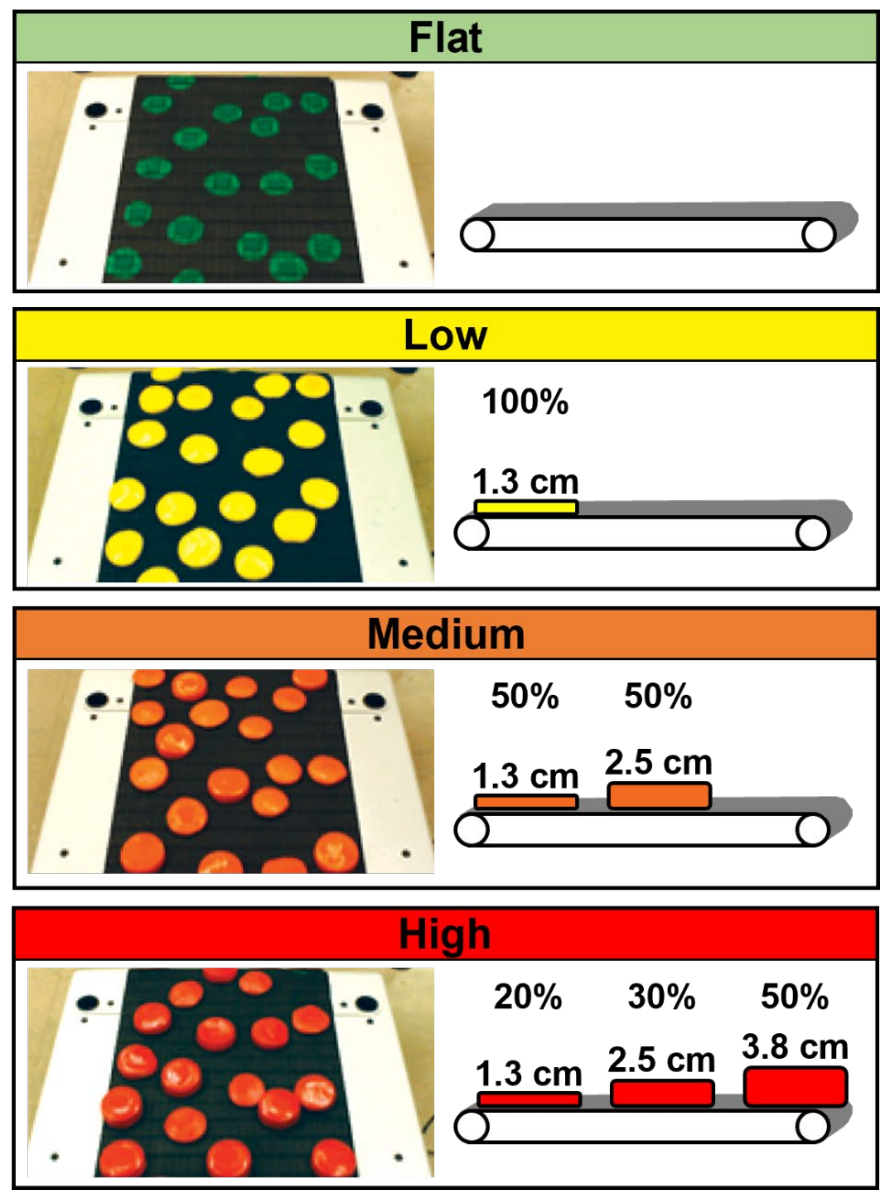

Fig 1. Uneven terrain treadmill. (A) We recorded participants' step timing along with the spatial movement of their sacrum as they walked over an uneven terrain treadmill. (B) We tested four terrain conditions by varying the height of the obstacles. 


\section{Walking Speed}

$(\mathrm{m} / \mathrm{s})$

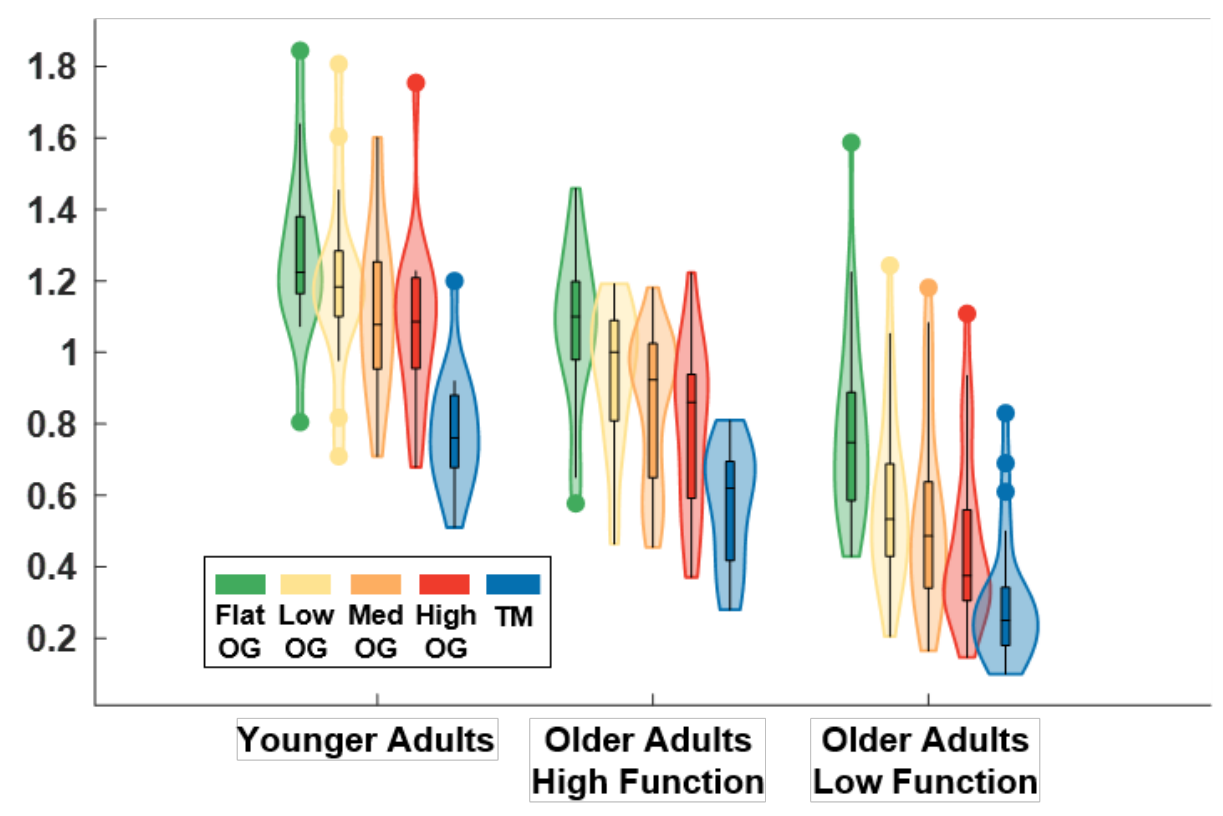

Fig 2. Violin plot showing the distribution of the self-selected overground (OG) walking speeds and the fixed treadmill (TM) speed for each participant group. Statistical tests were not performed, but overground walking speed tended to decrease with terrain unevenness for all groups. Lower-functioning older adults tended to walk slower than higher-functioning older adults. Younger adults tended to walk faster than higher-functioning older adults. The shaded regions represent the distribution of the data (across participants) by estimating the probability density function; each shaded region has equal area. The bottom of the box is the $25 \%$ percentile. The top of the box is the $75 \%$ percentile. The line in the middle of the box is the median. Whiskers extend from the bottom of the box to the smallest observation within 1.5 times the interquartile range. Whiskers similarly extend from the top of the box to the largest observation within 1.5 times the interquartile range. Individual data points lying outside the whiskers are plotted as circles. 
bioRxiv preprint doi: https://doi.org/10.1101/2022.03.01.482507; this version posted March 4, 2022. The copyright holder for this preprint (which was not certified by peer review) is the author/funder, who has granted bioRxiv a license to display the preprint in perpetuity. It is made available under aCC-BY-NC-ND 4.0 International license.
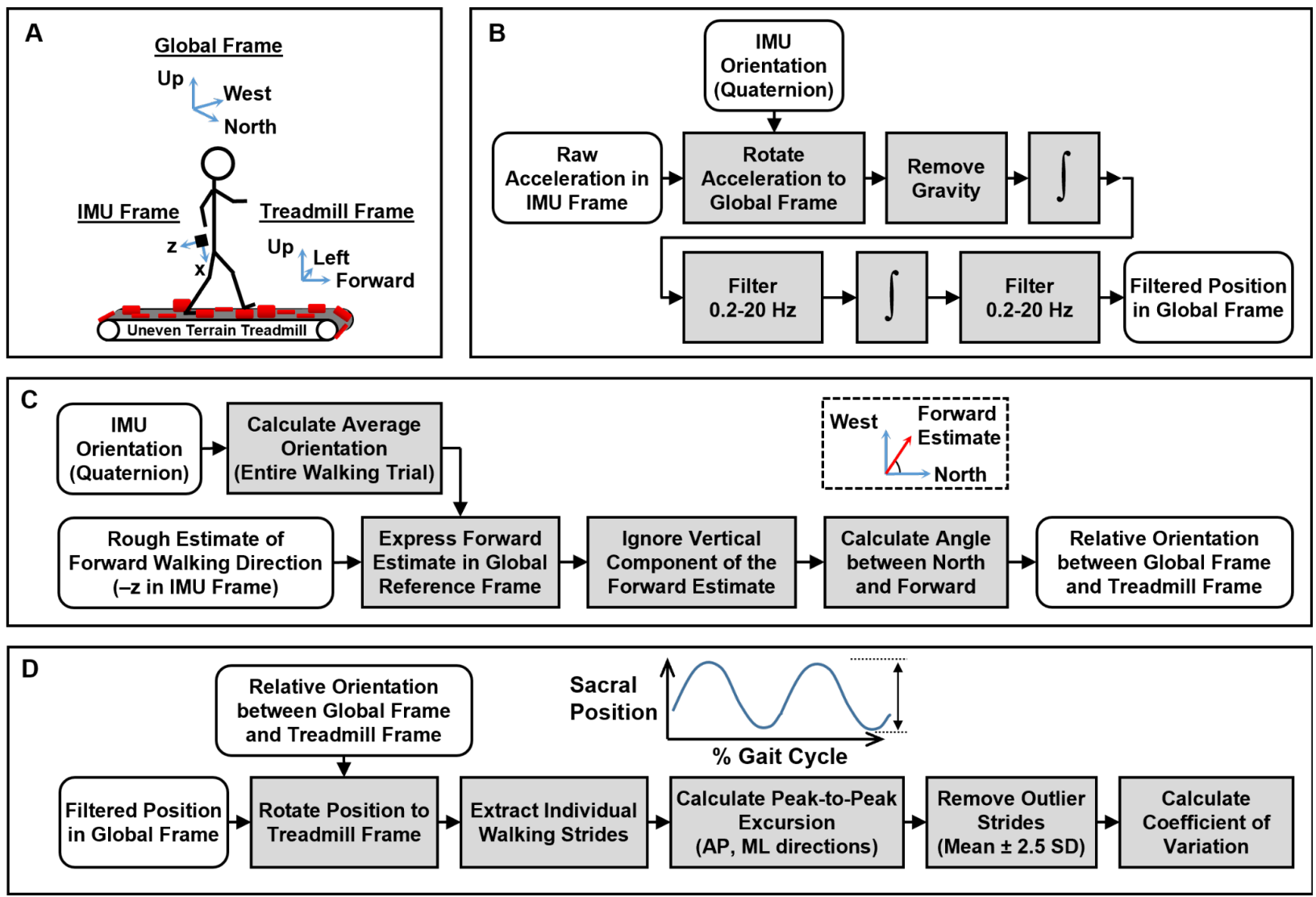

Fig 3. Inertial measurement unit (IMU) processing pipeline. (A) The IMU data, initially expressed in its local frame, was temporarily converted to a global frame, and ultimately analyzed in a treadmill fixed frame. (B) We calculated the movement of the sacrum in a global frame using the raw accelerations along with precalculated orientation information which was readily available on export (Motion Studio). (C) We used the average orientation of the IMU to find the forward walking direction. (D) We calculated the peak-to-peak excursion of the sacrum stride-by-side, in both the anteroposterior (AP) and mediolateral (ML) directions. Finally, we quantified the variability of the movement using the coefficient of variation. 
bioRxiv preprint doi: https://doi.org/10.1101/2022.03.01.482507; this version posted March 4, 2022. The copyright holder for this preprint (which was not certified by peer review) is the author/funder, who has granted bioRxiv a license to display the preprint in perpetuity. It is made available under aCC-BY-NC-ND 4.0 International license.

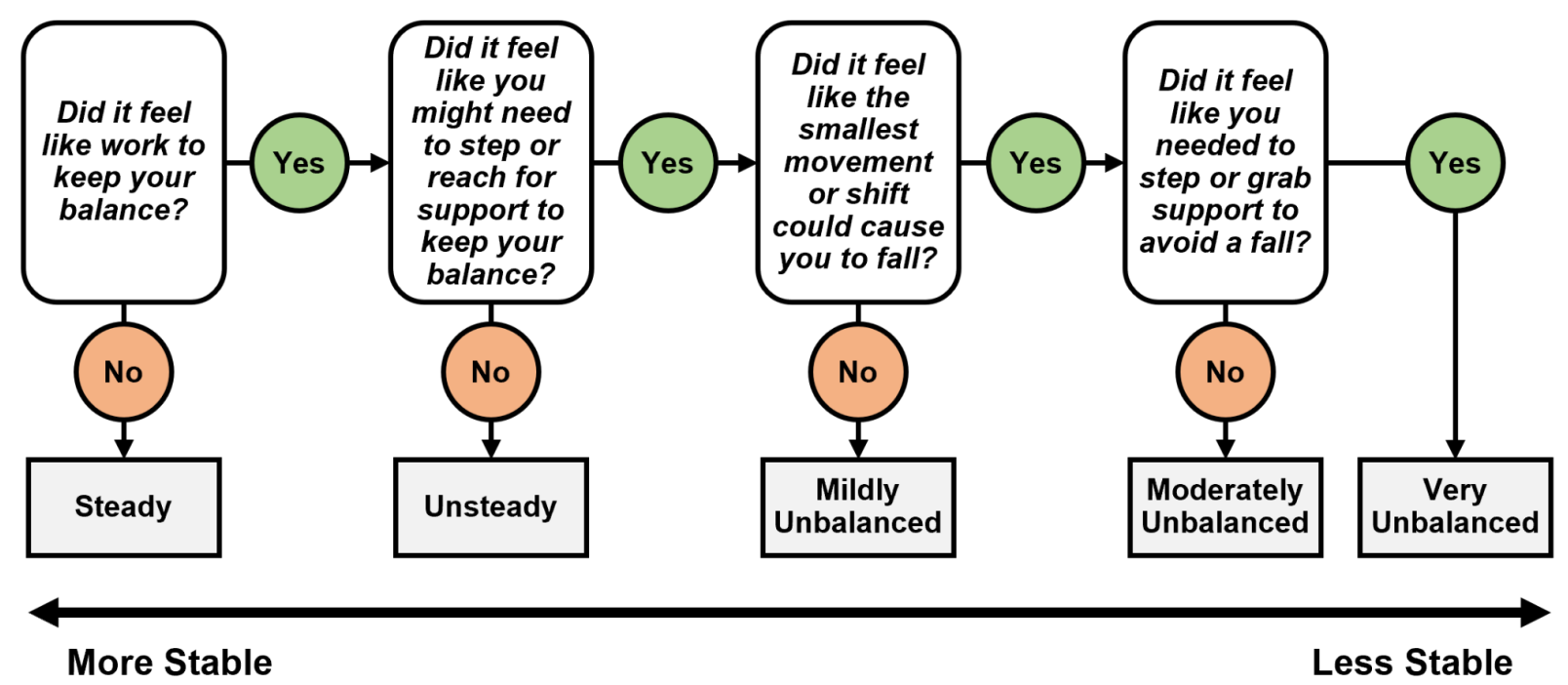

Fig 4. Flowchart for determining a participant's perceived stability. We asked participants to rate their perceived stability by answering a series of yes or no questions. We instructed them to only consider the official 3-minute portion of the trial when the treadmill speed was held constant. We asked them to ignore the transient moments before and after (i.e., when the treadmill is accelerating to the target speed or decelerating to a stop). 


\section{Step Duration (seconds)}

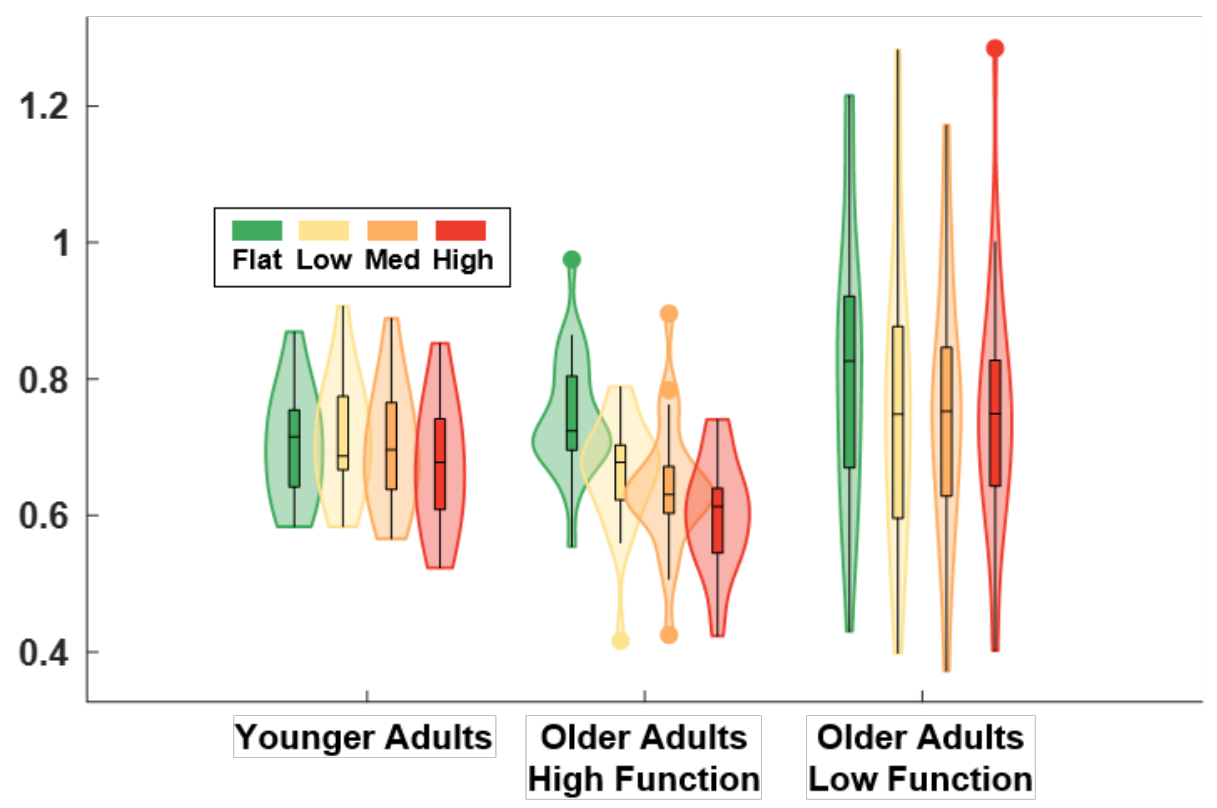

Fig 5. Violin plot showing the distribution of the step duration for each terrain condition and participant group. All groups showed a significant effect of decreased step duration for the Medium and High terrain conditions compared to Flat. Compared to higher-functioning older adults, lower-functioning older adults tended to have longer step durations for flat terrain, and younger adults tended to have shorter step durations, but neither effect was significant. The shaded regions represent the distribution of the data (across participants) by estimating the probability density function; each shaded region has equal area. The bottom of the box is the $25 \%$ percentile. The top of the box is the $75 \%$ percentile. The line in the middle of the box is the median. Whiskers extend from the bottom of the box to the smallest observation within 1.5 times the interquartile range. Whiskers similarly extend from the top of the box to the largest observation within 1.5 times the interquartile range. Individual data points lying outside the whiskers are plotted as circles. 


\section{Step Duration \\ Coefficient of Variation (\%)}

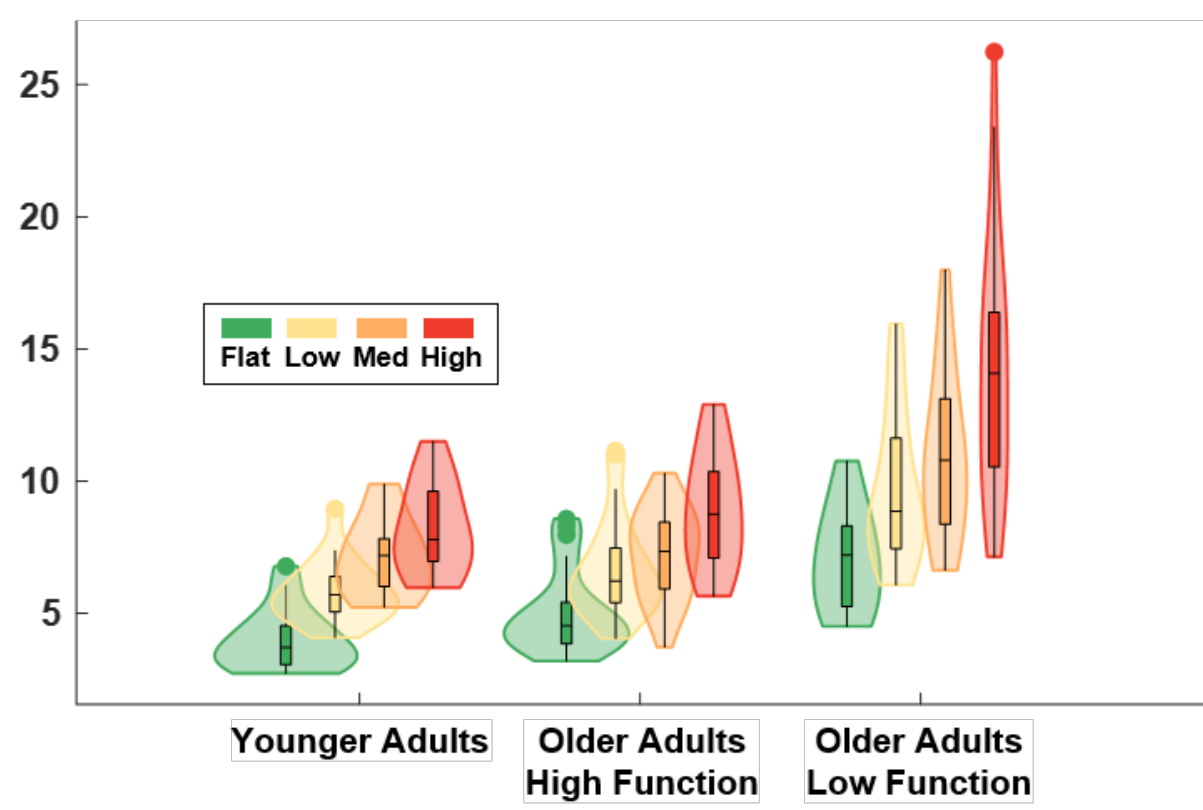

Fig 6. Violin plot showing the distribution of the step duration variability for each terrain condition and participant group. All groups showed significantly increased step duration variability for the Low, Medium, and High terrain conditions compared to Flat. The lower-functioning older adults walked with higher step duration variability than the higher-functioning older adults over flat terrain. The effect of the High terrain condition (relative to Flat) was stronger for the lower-functioning older adults compared to higher-functioning older adults. The shaded regions represent the distribution of the data (across participants) by estimating the probability density function; each shaded region has equal area. The bottom of the box is the $25 \%$ percentile. The top of the box is the $75 \%$ percentile. The line in the middle of the box is the median. Whiskers extend from the bottom of the box to the smallest observation within 1.5 times the interquartile range. Whiskers similarly extend from the top of the box to the largest observation within 1.5 times the interquartile range. Individual data points lying outside the whiskers are plotted as circles. 


\section{Anteroposterior Sacral Excursion Coefficient of Variation (\%)}

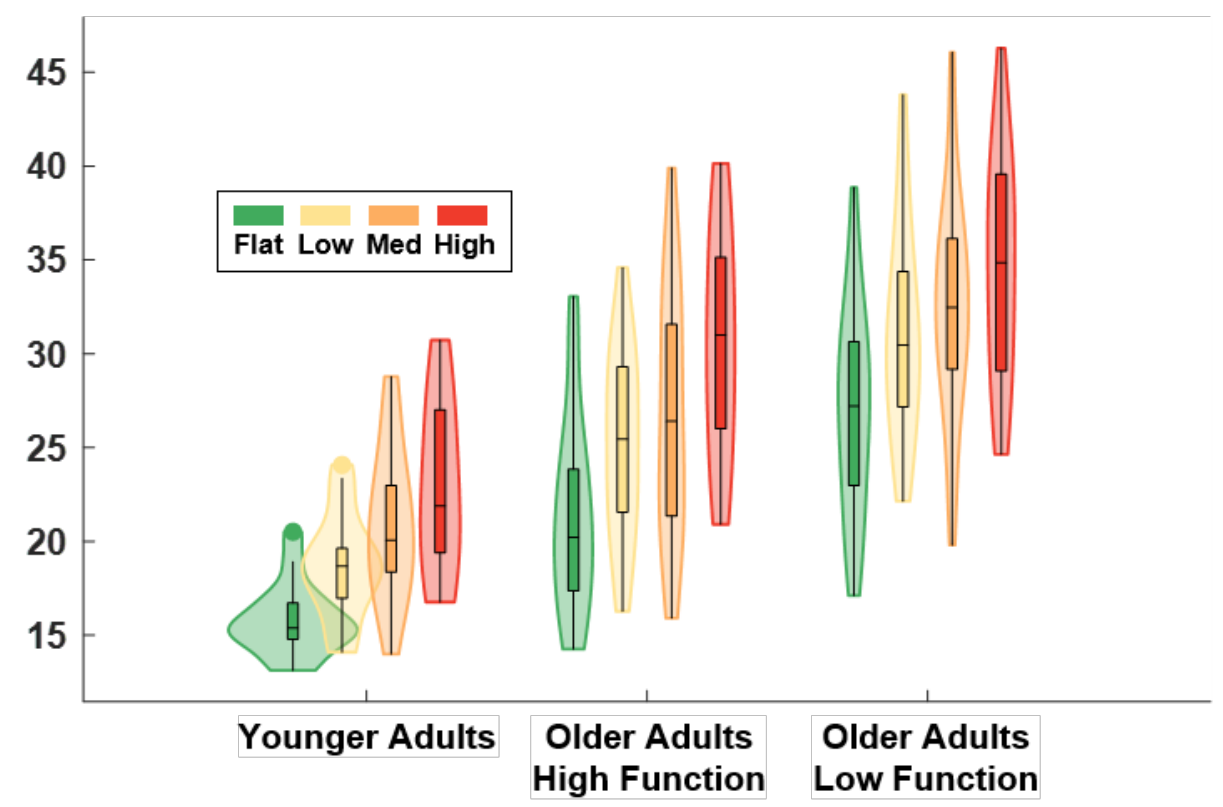

Fig 7. Violin plot showing the distribution of the sacral excursion variability in the anteroposterior direction for each terrain and participant group. All groups showed a significant effect of increased sacral variability in the anteroposterior direction for the Low, Medium, and High terrain conditions compared to Flat. Compared to the higher-functioning older adults, the lower-functioning older adults walked with significantly increased anteroposterior sacral excursion variability over flat terrain, while the younger adults walked with significantly less anteroposterior sacral excursion variability. The shaded regions represent the distribution of the data (across participants) by estimating the probability density function; each shaded region has equal area. The bottom of the box is the $25 \%$ percentile. The top of the box is the $75 \%$ percentile. The line in the middle of the box is the median. Whiskers extend from the bottom of the box to the smallest observation within 1.5 times the interquartile range. Whiskers similarly extend from the top of the box to the largest observation within 1.5 times the interquartile range. Individual data points lying outside the whiskers are plotted as circles. 


\section{Mediolateral Sacral Excursion Coefficient of Variation (\%)}

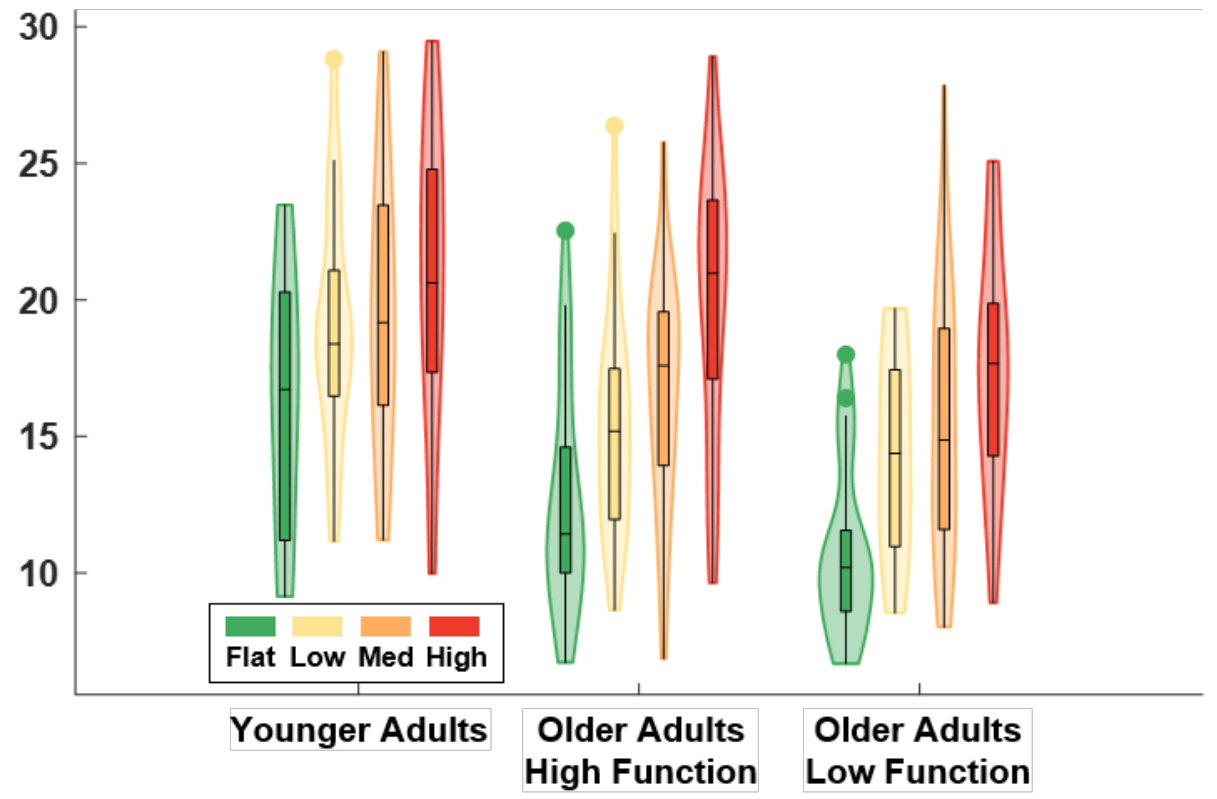

Fig 8. Violin plot showing the distribution of sacral excursion variability in the mediolateral direction for each terrain and participant group. All groups showed a significant effect of increased sacral variability in the mediolateral direction for the Low, Medium, and High terrain conditions compared to Flat. Compared to higherfunctioning older adults, younger adults walked with significantly increased mediolateral sacral excursion variability over Flat terrain. The shaded regions represent the distribution of the data (across participants) by estimating the probability density function; each shaded region has equal area. The bottom of the box is the $25 \%$ percentile. The top of the box is the $75 \%$ percentile. The line in the middle of the box is the median. Whiskers extend from the bottom of the box to the smallest observation within 1.5 times the interquartile range. Whiskers similarly extend from the top of the box to the largest observation within 1.5 times the interquartile range. Individual data points lying outside the whiskers are plotted as circles. 
bioRxiv preprint doi: https://doi.org/10.1101/2022.03.01.482507; this version posted March 4, 2022. The copyright holder for this preprint (which was not certified by peer review) is the author/funder, who has granted bioRxiv a license to display the preprint in perpetuity. It is made available under aCC-BY-NC-ND 4.0 International license.

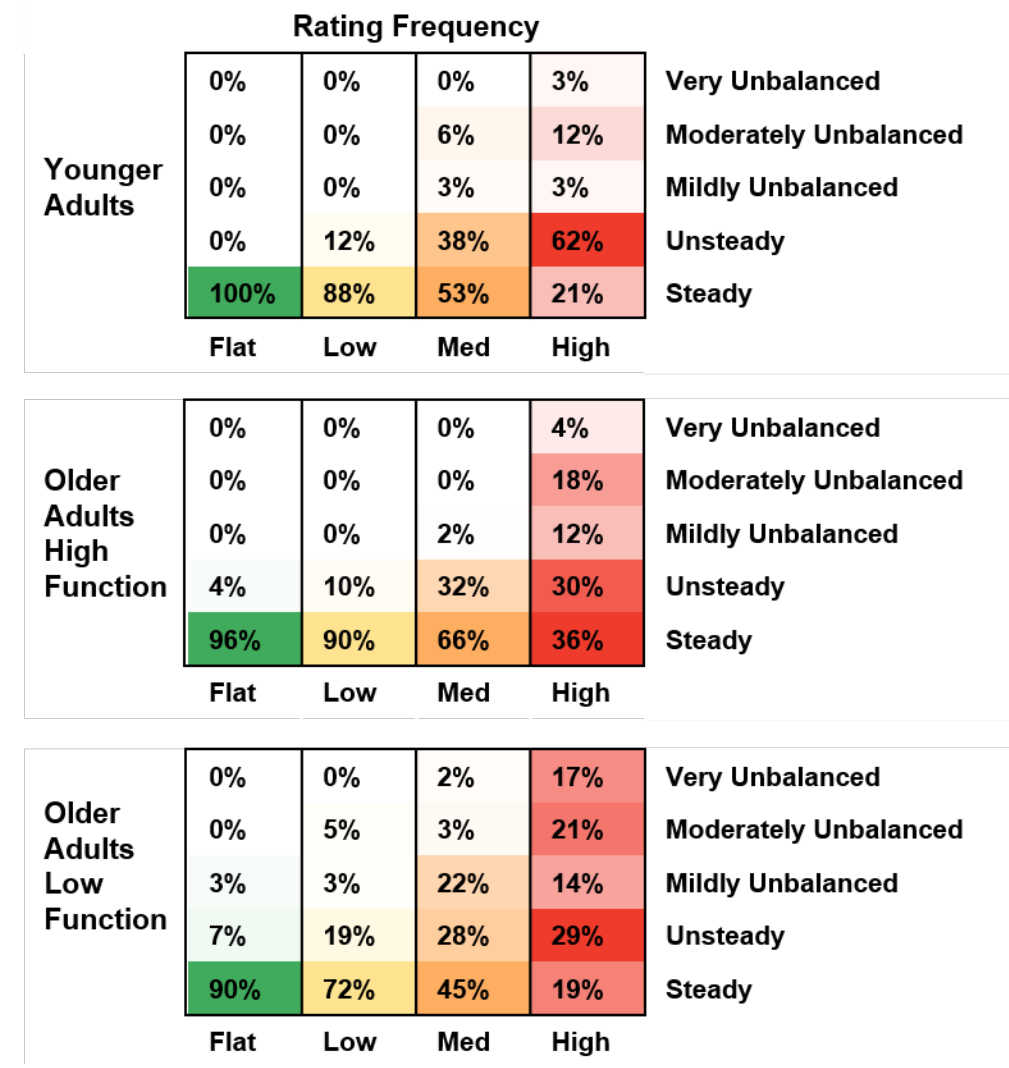

Fig 9. Perceived stability rating frequency. These values represent the percentage of walking trials that were rated a particular stability level as a function of the participant group and terrain. Within each group-terrain combination (i.e., within each column), colors are normalized from $0 \%$ (white) to the maximal value (solid green, yellow, orange, or red, depending on the terrain condition). This was done to emphasize the relative distribution of stability ratings and how they changed as a function of the terrain. Compared to the flat terrain, all uneven terrain conditions were significantly more likely to be perceived as less stable by all groups. Lower-functioning older adults were more likely to report feeling less stable than higher-functioning older adults over flat terrain. There was no significant difference between younger adults and higher-functioning older adults over flat terrain. 


\section{References}

1. Camicioli R, Howieson D, Lehman S, Kaye J. Talking while walking: The effect of a dual task in aging and Alzheimer's disease. Neurology. 1997;48: 955-958. doi:10.1212/WNL.48.4.955

2. Holtzer R, Mahoney JR, Izzetoglu M, Izzetoglu K, Onaral B, Verghese J. fNIRS study of walking and walking while talking in young and old individuals. Journals Gerontol - Ser A Biol Sci Med Sci. 2011;66 A: 879-887. doi:10.1093/gerona/glr068

3. Patel P, Lamar M, Bhatt T. Effect of type of cognitive task and walking speed on cognitive-motor interference during dual-task walking. Neuroscience. 2014;260: 140-148. doi:10.1016/j.neuroscience.2013.12.016

4. Springer S, Giladi N, Peretz C, Yogev G, Simon ES, Hausdorff JM. Dual-tasking effects on gait variability: The role of aging, falls, and executive function. Mov Disord. 2006;21: 950-957. doi:10.1002/mds.20848

5. Lindenberger U, Marsiske M, Baltes PB. Memorizing while walking: Increase in dual-task costs from young adulthood to old age. Psychol Aging. 2000;15: 417-436. doi:10.1037//0882-7974.15.3.417

6. Al-Yahya E, Johansen-Berg H, Kischka U, Zarei M, Cockburn J, Dawes H. Prefrontal Cortex Activation while Walking under Dual-Task Conditions in Stroke. Neurorehabil Neural Repair. 2016;30: 591-599. doi:10.1177/1545968315613864

7. Hill A, Bohil C, Lewis J, Neider M. Prefrontal cortex activity during walking while multitasking: An fnir study. Proc Hum Factors Ergon Soc Annu Meet. 2013;57: 1224-1228. doi:10.1177/1541931213571272

8. Parijat P, Lockhart TE. Effects of moveable platform training in preventing slip-induced falls in older adults. Ann Biomed Eng. 2012;40: 1111-1121. doi:10.1007/s10439-011-0477-0

9. Pai Y-C, Bhatt T, Yang F, Wang E. Perturbation training can reduce community-dwelling older adults' annual fall risk: A randomized controlled trial. Journals Gerontol - Ser A Biol Sci Med Sci. 2014;69: 15861594. doi:10.1093/gerona/glu087

10. Bhatt T, Yang F, Pai Y-C. Learning to resist gait-slip falls: Long-term retention in community-dwelling older adults. Arch Phys Med Rehabil. 2012;93: 557-564. doi:10.1016/j.apmr.2011.10.027

11. Shen X, Mak MKY. Technology-assisted balance and gait training rreduces falls in patients with Parkinson's disease: A randomized controlled trial with 12-month follow-up. Neurorehabil Neural Repair. 2015;29: 103-111. doi:10.1177/1545968314537559

12. Rieger MM, Papegaaij S, Steenbrink F, van Dieën JH, Pijnappels M. Perturbation-based gait training to improve daily life gait stability in older adults at risk of falling: Protocol for the REACT randomized controlled trial. BMC Geriatr. 2020;20: 167. doi:10.1186/s12877-020-01566-z

13. Lurie JD, Zagaria AB, Pidgeon DM, Forman JL, Spratt KF. Pilot comparative effectiveness study of surface perturbation treadmill training to prevent falls in older adults. BMC Geriatr. 2013;13: 49. doi:10.1186/14712318-13-49

14. Shimada H, Obuchi S, Furuna T, Suzuki T. New intervention program for preventing falls among frail elderly people: The effects of perturbed walking exercise using a bilateral separated treadmill. Am J Phys Med Rehabil. 2004;83: 493-499. doi:10.1097/01.PHM.0000130025.54168.91

15. Peterson SM, Ferris DP. Differentiation in theta and beta electrocortical activity between visual and physical perturbations to walking and standing balance. eNeuro. 2018;5: ENEURO.0207-18.2018. doi:10.1523/ENEURO.0207-18.2018

16. Hof AL, Duysens J. Responses of human ankle muscles to mediolateral balance perturbations during walking. Hum Mov Sci. 2018;57: 69-82. doi:10.1016/j.humov.2017.11.009 
bioRxiv preprint doi: https://doi.org/10.1101/2022.03.01.482507; this version posted March 4, 2022. The copyright holder for this preprin (which was not certified by peer review) is the author/funder, who has granted bioRxiv a license to display the preprint in perpetuity. It is made available under aCC-BY-NC-ND 4.0 International license.

17. Patla AE, Shumway-Cook A. Dimensions of Mobility: Defining the Complexity and Difficulty Associated with Community Mobility. J Aging Phys Act. 1999;7: 7-19. doi:10.1123/japa.7.1.7

18. Voloshina AS, Ferris DP. Design and validation of an instrumented uneven terrain treadmill. J Appl Biomech. 2018;34: 236-239. doi:10.1123/jab.2016-0322

19. Santuz A, Ekizos A, Eckardt N, Kibele A, Arampatzis A. Challenging human locomotion: Stability and modular organisation in unsteady conditions. Sci Rep. 2018;8: 2740. doi:10.1038/s41598-018-21018-4

20. Kent JA, Sommerfeld JH, Mukherjee M, Takahashi KZ, Stergiou N. Locomotor patterns change over time during walking on an uneven surface. J Exp Biol. 2019;222: jeb202093. doi:10.1242/jeb.202093

21. Voloshina AS, Kuo AD, Daley MA, Ferris DP. Biomechanics and energetics of walking on uneven terrain. J Exp Biol. 2013;216: 3963-3970. doi:10.1242/jeb.081711

22. Wang J, Gillette JC. Carrying asymmetric loads while walking on an uneven surface. Gait Posture. 2018;65: 39-44. doi:10.1016/j.gaitpost.2018.06.173

23. Clark DJ, Manini TM, Ferris DP, Hass CJ, Brumback BA, Cruz-Almeida Y, et al. Multimodal Imaging of Brain Activity to Investigate Walking and Mobility Decline in Older Adults (Mind in Motion Study): Hypothesis, Theory, and Methods. Front Aging Neurosci. 2020;11: 358. doi:10.3389/fnagi.2019.00358

24. Guralnik JM, Simonsick EM, Ferrucci L, Glynn RJ, Berkman LF, Blazer DG, et al. A short physical performance battery assessing lower extremity function: Association with self-reported disability and prediction of mortality and nursing home admission. J Gerontol. 1994;49: M85-94. doi:10.1093/geronj/49.2.M85

25. Burns GT, Deneweth Zendler J, Zernicke RF. Validation of a wireless shoe insole for ground reaction force measurement. J Sports Sci. 2019;37: 1129-1138. doi:10.1080/02640414.2018.1545515

26. Espy D, Reinthal A, Meisel S. Intensity of Balance Task Intensity, as Measured by the Rate of Perceived Stability, is Independent of Physical Exertion as Measured by Heart Rate. J Nov Physiother. 2017;7: 343. doi:10.4172/2165-7025.1000343

27. Bruijn SM, Meijer OG, Beek PJ, van Dieën JH. Assessing the stability of human locomotion: A review of current measures. J R Soc Interface. 2013;10: 20120999. doi:10.1098/rsif.2012.0999

28. Reuter-Lorenz PA, Cappell KA. Neurocognitive aging and the compensation hypothesis. Curr Dir Psychol Sci. 2008;17: 177-182. doi:10.1111/j.1467-8721.2008.00570.x

29. Fettrow T, Hupfeld K, Tays G, Clark DJ, Reuter-Lorenz PA, Seidler RD. Brain activity during walking in older adults: Implications for compensatory versus dysfunctional accounts. Neurobiol Aging. 2021;105: 349-364. doi:10.1016/j.neurobiolaging.2021.05.015 
bioRxiv preprint doi: https://doi.org/10.1101/2022.03.01.482507; this version posted March 4. 2022. The copyright holder for this preprint (which was not certified by peer review) is the author/funder, who has granted bioRxiv a license to display the preprint in perpetuity. It is made available under aCC-BY-NC-ND 4.0 International license.

\section{Supporting information}

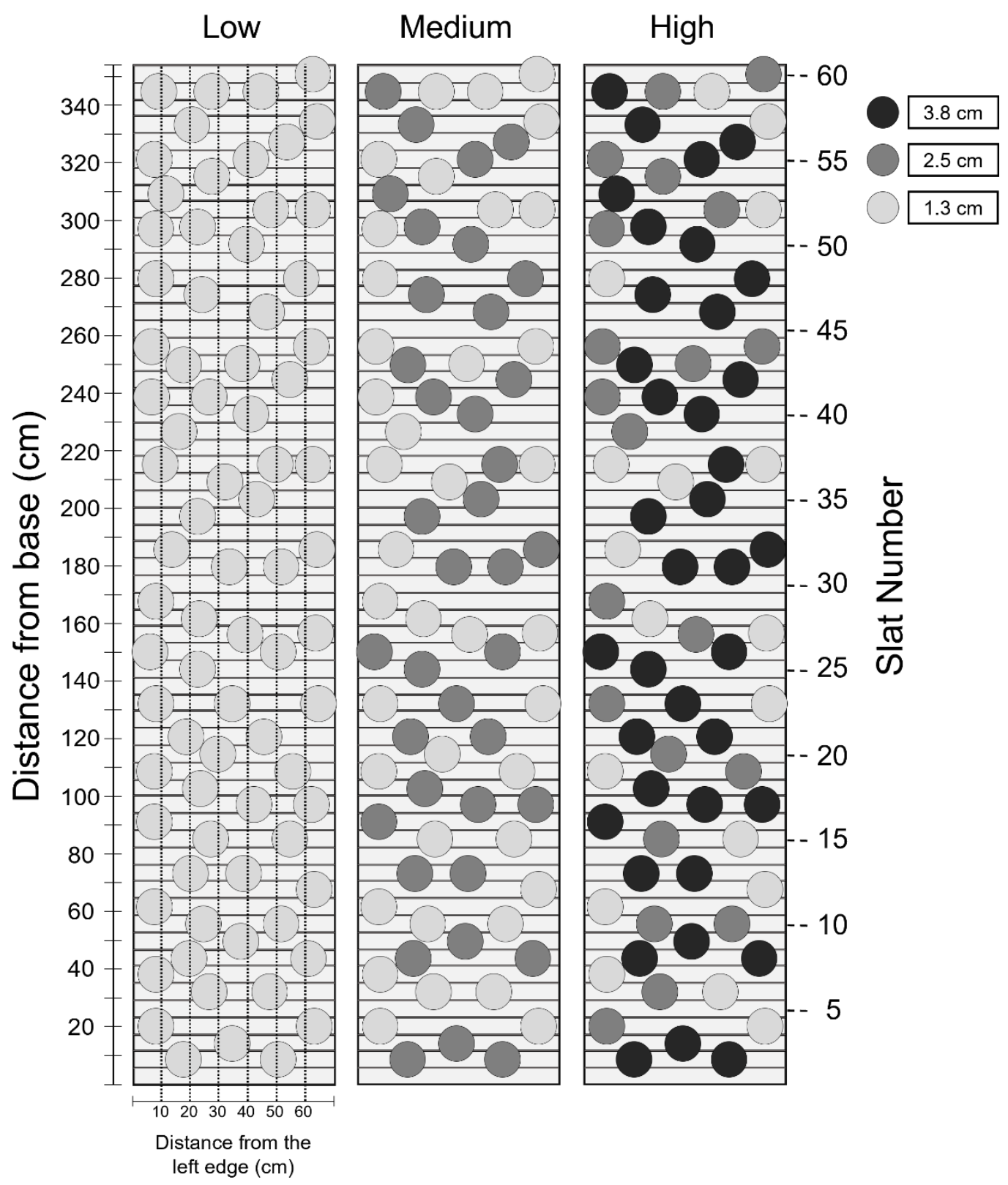

S1 Fig. Obstacle positioning on treadmill. Obstacles were placed systematically so that the terrain conditions were repeatable across participants. The total weight of the added foam obstacles was $3.5,5.2$, and 7.9 pounds $(1.6,2.4,3.6 \mathrm{~kg})$ for the Low, Medium, and High conditions, respectively. 
bioRxiv preprint doi: https://doi.org/10.1101/2022.03.01.482507: this version posted March 4 2022. The copyright holder for this preprin (which was not certified by peer review) is the author/funder, who has granted bioRxiv a license to display the preprint in perpetuity. It is made available under aCC-BY-NC-ND 4.0 International license.

S2 Table. Statistical model results for step duration (s).

\begin{tabular}{|c|r|r|r|r|r|c|}
\hline & Value & Std. Error & \multicolumn{1}{|c|}{ DF } & t-value & p-value & Sig. \\
\hline Intercept & & & & & & \\
\hline HO, Flat & 0.743 & 0.0296 & 200 & 25.12 & 0.0000 & ${ }^{*}$ \\
\hline Group & & & & & & \\
\hline YA & & & & & & \\
\hline LO & -0.040 & 0.0464 & 200 & -0.86 & 0.3925 & \\
\hline Terrain & 0.076 & 0.0403 & 200 & 1.88 & 0.0614 & \\
\hline Low & & & & & & \\
\hline Medium & -0.079 & 0.0419 & 200 & -1.89 & 0.0601 & \\
\hline High & -0.101 & 0.0419 & 200 & -2.40 & 0.0171 & ${ }^{*}$ \\
\hline & & 0.0418 & 200 & -3.37 & 0.0009 & ${ }^{*}$ \\
\hline Interaction & & & & & \\
\hline YA Low & 0.090 & 0.0658 & 200 & 1.37 & 0.1730 & \\
\hline YA Medium & 0.097 & 0.0656 & 200 & 1.48 & 0.1410 & \\
\hline YA High & 0.110 & 0.0656 & 200 & 1.67 & 0.0964 & \\
\hline & & & & & & \\
\hline LO Low & 0.026 & 0.0572 & 200 & 0.45 & 0.6538 & \\
\hline LO Medium & 0.038 & 0.0571 & 200 & 0.67 & 0.5027 & \\
\hline LO High & 0.068 & 0.0572 & 200 & 1.18 & 0.2383 & \\
\hline
\end{tabular}

$\mathrm{DF}$, degrees of freedom; $\mathrm{HO}$, higher-functioning old adults, $\mathrm{LO}=$ lower-functioning old adults; YA, younger adults. 
bioRxiv preprint doi: https://doi.org/10.1101/2022.03.01.482507: this version posted March 4 2022. The copyright holder for this preprin (which was not certified by peer review) is the author/funder, who has granted bioRxiv a license to display the preprint in perpetuity. It is made available under aCC-BY-NC-ND 4.0 International license.

S3 Table. Statistical model results for step duration variability (\%).

\begin{tabular}{|c|c|c|c|c|c|c|}
\hline & Value & Std. Error & DF & t-value & $p$-value & Sig. \\
\hline \multicolumn{7}{|l|}{ Intercept } \\
\hline $\mathrm{HO}$, Flat & 5.02 & 0.493 & 200 & 10.19 & 0.0000 & * \\
\hline \multicolumn{7}{|l|}{ Group } \\
\hline YA & -1.04 & 0.774 & 200 & -1.35 & 0.1796 & \\
\hline LO & 1.97 & 0.672 & 200 & 2.93 & 0.0038 & * \\
\hline \multicolumn{7}{|l|}{ Terrain } \\
\hline Low & 1.66 & 0.697 & 200 & 2.38 & 0.0182 & * \\
\hline Medium & 2.20 & 0.697 & 200 & 3.16 & 0.0018 & * \\
\hline High & 3.86 & 0.697 & 200 & 5.54 & 0.0000 & * \\
\hline \multicolumn{7}{|l|}{ Interaction } \\
\hline YA Low & 0.17 & 1.095 & 200 & 0.15 & 0.8794 & \\
\hline YA Medium & 0.94 & 1.095 & 200 & 0.85 & 0.3937 & \\
\hline YA High & 0.33 & 1.095 & 200 & 0.30 & 0.7610 & \\
\hline LO Low & 1.06 & 0.954 & 200 & 1.11 & 0.2693 & \\
\hline LO Medium & 1.77 & 0.951 & 200 & 1.86 & 0.0640 & \\
\hline LO High & 3.22 & 0.954 & 200 & 3.37 & 0.0009 & * \\
\hline
\end{tabular}

$\mathrm{DF}$, degrees of freedom; $\mathrm{HO}$, higher-functioning old adults, LO = lower-functioning old adults; YA, younger adults. 
bioRxiv preprint doi: https://doi.org/10.1101/2022.03.01.482507: this version posted March 4 2022. The copyright holder for this preprin (which was not certified by peer review) is the author/funder, who has granted bioRxiv a license to display the preprint in perpetuity. It is made available under aCC-BY-NC-ND 4.0 International license.

S4 Table. Statistical model results for anteroposterior excursion variability (\%).

\begin{tabular}{|c|c|c|c|c|c|c|}
\hline & Value & Std. Error & DF & t-value & $p$-value & Sig. \\
\hline \multicolumn{7}{|l|}{ Intercept } \\
\hline $\mathrm{HO}$, Flat & 21.35 & 1.05 & 200 & 20.41 & 0.0000 & * \\
\hline \multicolumn{7}{|l|}{ Group } \\
\hline YA & -5.55 & 1.64 & 200 & -3.38 & 0.0009 & * \\
\hline LO & 5.61 & 1.43 & 200 & 3.93 & 0.0001 & * \\
\hline \multicolumn{7}{|l|}{ Terrain } \\
\hline Low & 3.66 & 1.48 & 200 & 2.48 & 0.0141 & * \\
\hline Medium & 5.32 & 1.48 & 200 & 3.59 & 0.0004 & * \\
\hline High & 9.03 & 1.48 & 200 & 6.10 & 0.0000 & * \\
\hline \multicolumn{7}{|l|}{ Interaction } \\
\hline YA Low & -0.81 & 2.33 & 200 & -0.35 & 0.7264 & \\
\hline YA Medium & -0.17 & 2.33 & 200 & -0.07 & 0.9409 & \\
\hline YA High & -2.10 & 2.33 & 200 & -0.91 & 0.3665 & \\
\hline LO Low & 0.43 & 2.03 & 200 & 0.21 & 0.8303 & \\
\hline LO Medium & 0.11 & 2.02 & 200 & 0.05 & 0.9566 & \\
\hline LO High & -1.49 & 2.03 & 200 & -0.74 & 0.4629 & \\
\hline
\end{tabular}

$\mathrm{DF}$, degrees of freedom; $\mathrm{HO}$, higher-functioning old adults, $\mathrm{LO}=$ lower-functioning old adults; YA, younger adults. 
bioRxiv preprint doi: https://doi.org/10.1101/2022.03.01.482507; this version posted March 4, 2022. The copyright holder for this preprin (which was not certified by peer review) is the author/funder, who has granted bioRxiv a license to display the preprint in perpetuity. It is made available under aCC-BY-NC-ND 4.0 International license.

S5 Table. Statistical model results for mediolateral excursion variability (\%).

\begin{tabular}{|c|c|c|c|c|c|c|}
\hline & Value & Std. Error & DF & t-value & $p$-value & Sig. \\
\hline \multicolumn{7}{|l|}{ Intercept } \\
\hline $\mathrm{HO}$, Flat & 12.48 & 0.99 & 200 & 12.60 & 0.0000 & * \\
\hline \multicolumn{7}{|l|}{ Group } \\
\hline YA & 3.82 & 1.55 & 200 & 2.47 & 0.0144 & * \\
\hline LO & -1.66 & 1.34 & 200 & -1.24 & 0.2163 & \\
\hline \multicolumn{7}{|l|}{ Terrain } \\
\hline Low & 2.84 & 1.41 & 200 & 2.02 & 0.0452 & * \\
\hline Medium & 4.05 & 1.41 & 200 & 2.88 & 0.0044 & * \\
\hline High & 7.09 & 1.40 & 200 & 5.06 & 0.0000 & * \\
\hline \multicolumn{7}{|l|}{ Interaction } \\
\hline YA Low & -0.24 & 2.20 & 200 & -0.11 & 0.9143 & \\
\hline YA Medium & -0.99 & 2.19 & 200 & -0.45 & 0.6528 & \\
\hline YA High & -2.12 & 2.18 & 200 & -0.97 & 0.3320 & \\
\hline LO Low & 0.85 & 1.91 & 200 & 0.44 & 0.6584 & \\
\hline LO Medium & 0.46 & 1.91 & 200 & 0.24 & 0.8099 & \\
\hline LO High & -0.26 & 1.91 & 200 & -0.13 & 0.8930 & \\
\hline
\end{tabular}

DF, degrees of freedom; HO, higher-functioning old adults; LO = lower-functioning old adults; YA, younger adults. 
bioRxiv preprint doi: https://doi.org/10.1101/2022.03.01.482507; this version posted March 4, 2022. The copyright holder for this preprint (which was not certified by peer review) is the author/funder, who has granted bioRxiv a license to display the preprint in perpetuity. It is made available under aCC-BY-NC-ND 4.0 International license.

S6 Table. Statistical model results for perceived stability ratings.

\begin{tabular}{|c|r|r|r|c|}
\hline & \multicolumn{1}{|c|}{ OR } & \multicolumn{1}{|c|}{$\mathbf{2 . 5 \%}$} & $\mathbf{9 7 . 5 \%}$ & Sig. \\
\hline Group & & & & \\
\hline YA & 1.22 & 0.721 & 2.05 & \\
\hline LO & 2.83 & 1.798 & 4.50 & ${ }^{*}$ \\
\hline Terrain & & & & \\
\hline Low & 4.15 & 1.799 & 10.82 & ${ }^{*}$ \\
\hline Medium & 16.96 & 7.830 & 42.56 & ${ }^{*}$ \\
\hline High & 68.03 & 31.010 & 172.67 & ${ }^{*}$ \\
\hline & & & & \\
\hline
\end{tabular}

$\mathrm{HO}$, higher-functioning old adults; LO = lower-functioning old adults; OR, odds ratio; YA, younger adults.

If odds ratio $>1$, the effect is in the direction of less stable walking.

If odds ratio $<1$, the effect is in the direction of more stable walking.

If odds ratio confidence interval $[2.5 \%, 97.5 \%]$ contains 1 , the effect is not significant. 
bioRxiv preprint doi: https://doi.org/10.1101/2022 03 01.482507; this version posted March 4, 2022. The copyright holder for this preprint (which was not certified by peer review) is the author/funder, who has granted bioRxiv a license to display the preprint in perpetuity. It is made available under aCC-BY-NC-ND 4.0 International license.

S7 Spreadsheet. Raw data used for statistical analyses. Dataset includes raw values of step duration; step duration variability; anteroposterior sacral excursion variability; mediolateral sacral excursion variability; and the rating of perceived stability for each participant and for each of the four uneven terrain treadmill conditions. Also included are the age, sex, and group information of each participant; the self-selected walking speeds for overground walking for each of the four terrains; and the speeds that were used for treadmill walking. For older adults, their short physical performance battery scores are also included. 